\title{
RAZPRAVE
}

\section{KRAS FRMILSKE DOLINE V KRAJINSKEM PARKU BOČ-DONAČKA GORA}

\author{
AVTOR \\ Igor Bahar \\ Kidričeva 49, SI - 3250 Rogaška Slatina, Slovenija; igor_bahar@hotmail.com
}

DOI: $10.3986 / G V 90101$

UDK: 911.2:551.44(497.43)

COBISS: 1.01

\section{IZVLEČEK}

\section{Kras Frmilske doline v Krajinskem parku Boč-Donačka gora}

$V$ Krajinskem parku Boč-Donačka gora, na vzhodnem robu slovenskega krasa, imamo šolski primer pokrajine v kateri se je zakrasevanje površja "pravkar " pričelo. Ohranjene so oblike iz katerih lahko spoznamo postopni prehod iz rečnega $v$ kraški relief. Frmilska dolina je bila prvotno porečje v nekarbonatnih kamninah, ki pa je zaradi erozije "nasedlo" na karbonatno podlago in se prestavilo v podzemlje. Iz nekdaj enotnega porečja je nastalo 14 aktivnih slepih dolin in 14 zakraselih rečnih dolin brez površinskega vodnega toka. Razčlenjen površinski odtok se nadaljuje v sklenjen podzemni odtok vse do kraških izvirov pri Studeniškem samostanu v dolini Dravinje. Na območju Frmilske doline lahko opazujemo še več rečnih in kraških pojavov: jame, izvire, presihajočo mlako, udorno steno, sufozijske vrtače in požiralnike v nekarbonatnih kamninah, rečne terase in suhe ali fosilne meandre v zakraseli dolini, obvisele doline in spodmole.

\section{KLJUČNE BESEDE}

kraški relief, rečni relief, slepa dolina, sufozijska vrtača, sufozijski požiralnik, fosilni meandri, obvisela dolina, Frmilska dolina

\begin{abstract}
Karst of Frmile Valley in the Landscape Park Boč-Donačka Gora

In the Landscape Park Boč-Donačka Gora (eastern Slovenia), on the eastern edge of the Slovenian karst, we have a textbook example of a territory in which the karstic process has "just " started. There are preserved features, which allow us to understand the transformation from a fluvial landscape to a karstic one. Frmile Valley was originally a river valley in non-carbonate rocks, but due to erosion it became stranded on carbonate rocks. Its waters were mostly transferred to the underground drainage. Fragmentation of the former river valley formed 14 active blind valleys and 14 inactive river valleys that already lost all surface water to the underground drainage. The disconnected surface runoff recharges the same karst aquifer which springs are located at the Studenice Monastery in the Dravinja Valley. In the area of Frmile Valley several fluvial and karstic features can be observed, i.e. caves, springs, a periodic pond, a hill slope collapsed into an underground cave, numerous suffosion dolines and ponors in the non-carbonate rocks, river terraces, dry or fossil meanders in karst valley, hanging valleys, a rock shelter.
\end{abstract}

\section{KEY WORDS}

karst landscape, fluvial landscape, blind valley, suffosion doline, suffosion ponor, fossil meanders, hanging valley, Frmile Valley

Uredništvo je prispevek prejelo 10. decembra 2017. 


\section{Uvod}

Frmilska dolina se nahaja v vzhodnem delu Slovenije, v Krajinskem parku Boč-Donačka gora, med Bočem $(980 \mathrm{~m})$ na zahodu in Plešivcem $(821 \mathrm{~m})$ na jugovzhodu, na severu pa se proti Studenicam spusti v dolino Dravinje. Obdajajo jo kraški osamelci Drevesnica (vzhodni greben Boča), Kisovec (743 m), Tolsti vrh (Rogaška Slatina ... 1989; Občina ... 1995) ali Stavski vrh (777 m) (Medmrežje 1; Temeljni ... 1991), Šnajderjev hrib (743 m) in Hrastovec (791 m) (slika 1).

Frmilsko dolino delimo na Zgornjo Frmilsko dolino in pritočno Malotravniško dolino. Obe se stikata na Frmilah ( $\sim 625 \mathrm{~m}$ ) (na zemljevidih napačno zapisano kot Formila), ki so dale dolini ime, ta pa se prek Frmilskega sedla nadaljuje še v grapo Toplega potoka do Studenic v dolini Dravinje (slika 1).

Kraški pojavi v tem delu Slovenije so že dolgo poznani, vendar je bilo doslej opravljeno le malo raziskav. Te so v prvi opravili vrsti raziskovalci kraških jam (Novak 1969a; 1969b; Brancelj 1984; Trobič 1984), v povezavi s pretakanjem voda pa Novak (1982) in Gospodarč (1982). Pomembnejše podatke je doslej prispeval zlasti Novak (1974), ki je s sledilnim poskusom dokazal povezanost požiralnika na Mlinišču (slika 3) s kraškimi izviri v Studenicah (slika 1). Te povezave požiralnikov z izviri v Studenicah so sicer znane že iz ljudskih pripovedi (Pažon 2016).

Ker je na obravnavanem območju mnogo reliefnih oblik, ki še niso bile podrobneje preučene in opisane, smo začeli z njihovim sistematičnim kartiranjem tako na karbonatnih kot nekarbonatnih kamninah (Zemljepisni ... 2013; 2016; 2017). V merilu 1:5000 (slike 2-7) smo kartirali litološke meje med karbonatnimi in nekarbonatnimi kamninami ter značilne reliefne oblike. Tovrstni podatki so nujni za razumevanje opisanih kraških pojavov. Šele s tem se je namreč pokazalo, da so kraški pojavi v obravnavani pokrajini drugačni od številnih drugih primerov osamelega krasa in slepih dolin po Sloveniji.

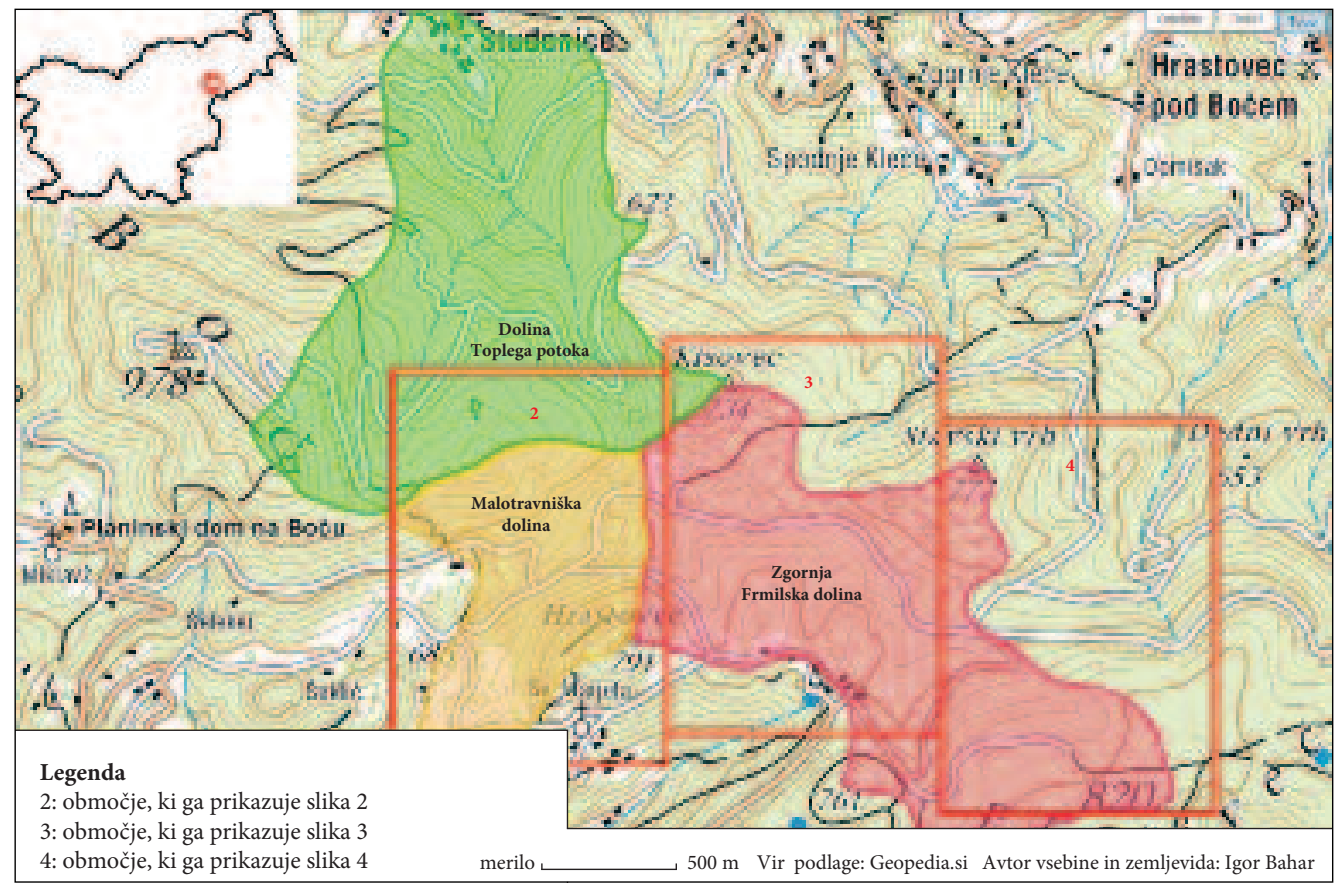

Slika 1: Lega in delitev Frmilske doline. 


\section{Geologija}

Geološka zgradba območja je bila prvič natančno prikazana v članku Novaka (1974), kasneje pa na Osnovni geološki karti (Aničić in Juriša 1985a; 1985b). Vendar pa sta na območju Frmilske doline oba zemljevida dokaj netočna, predvsem zaradi velikega merila, s katerim ni mogoče predstaviti vso kamninsko pestrost, ki se menja na vsega nekaj deset metrskih razdaljah. Nedavno je bi bil objavljen tudi manjši geološki zemljevid (Trček in Leis 2017, 51), katerega natančnost pa po naših terenskih opažanjih (slike 2-4) tudi ni najboljša.

Hribovje med Bočem in Plešivcem je tektonsko močno preoblikovano. Eno ob drugi najdemo kamnine iz srednjega miocena stare okoli 15 milijonov let in triasne kamnine stare okoli 240 milijonov let, ob njih pa še srednje in spodnje permske kamnine stare okoli 280 milijonov let. Skoraj vsi stiki med temi kamninami so na geološkem zemljevidu označeni kot tektonski. Na severni strani Boča so triasne kamnine narinjene na miocensko podlago. Med Plešivcem in Rogaško Slatino imamo najbolj značilen primer neskladnega reliefa v Sloveniji. Rogaška Slatina $(230 \mathrm{~m})$ je v jedru Pletovarsko-Maceljske antiklinale, vrh Plešivca $(820 \mathrm{~m}$ ) pa v jedru Haloške sinklinale, ki je iz nekoliko mlajših kamnin (Aničić in Juriša 1985a; 1985b).

Razen na Plešivcu, ki je v celoti iz nekarbonatnih kamnin, imamo na površju obravnavanega območja povsod (tam, kjer še niso bile erozijsko odstranjene) od nekaj centimetrov do nekaj deset metrov debele nekarbonatne kamnine, ki prekrivajo več $100 \mathrm{~m}$ debelo podlago iz karbonatnih kamnin. Med nekarbonatnimi kamninami prevladujejo kremenovi peščenjaki, kremenovi konglomerati in glinavci. $\mathrm{Na}$ geoloških zemljevidih so tem kamninam mestoma določili permsko starost, drugod pa oligocensko oziroma miocensko starost. Tam, kjer se stikajo, te na videz podobne kamnine neopazno prehajajo iz ene v drugo. Karbonatne kamnine v podlagi so apnenci in dolomiti permske in triasne starosti, ki so pod nekarbonatno krovnino globoko zakraseli, kar dokazujejo sufozijske vrtače in požiralniki ter doline brez površinskega vodnega toka na nekarbonatnih kamninah.

Od Finkoštne planine, prek terase Tolstega (Stavskega) vrha, 2. Frmilske slepe doline, terase Šnajderjevega hriba ter Velikega Travnika do Svete Marjete in še naprej, se vleče skoraj sklenjen ozek pas debelozrnatega kremenovega konglomerata permske starosti (Aničić in Juriša 1985a), ki ima mestoma izdanke v obliki pečin. Ta konglomerat je po svojih značilnostih opazno drugačen od drugih konglomeratov in bi se na prihodnjih podrobnih geoloških zemljevidih lahko označil kot samostojna enota. Zaradi lažjega razlikovanja od drugih konglomeratov, je $\mathrm{v}$ tem članku poimenovan kot "glažutarski konglomerat « (na podlagi ustnega izročila, da so to kamnino izkoriščali kot surovino za izdelavo stekla v Attemsovi glažuti v Jelovcu pod Sveto Marjeto). Pri konglomeratih Plešivca (miocen) in Podkisovške planote (perm) so prodniki običajno manjši in obdani z debelim veznim cementom. Ob preperevanju veznega cementa, prodniki izpadajo iz konglomerata in v njem ostajajo luknje. Glažutarski konglomerat vsebuje zelo malo veziva, veliki kremenovi prodniki pa pri razpadanju kamnine prej pokajo kot izpadajo. V zelo redkih vzorcih konglomerata pod Tolstim vrhom smo našli redke nezaobljene kose drugih kamnin, s pomočjo katerih bi v prihodnosti lahko preverili starost. Ta konglomerat navidezno sledi pasu permskih apnencev, vendar ponekod leži tudi na triasnih apnencih in dolomitih. Glažutarski konglomerat je na dnu 2. Frmilske slepe doline in na območju Velikega Travnika prekrit s preperino ali s kvartarnim nanosom miocenskega kremenovega peščenjaka. Skupaj s permskimi apnenci označuje položaj jedra navidezne antiklinale, ki je vzporedna haloški sinklinali (Aničić in Juriša 1985a). Triasne kamnine Boča se pojavljajo na severozahodnem krilu te navidezne antiklinale.

Tektonska preoblikovanost ozemlja je opisala Žibretova (2016), ki je prepoznala štiri tektonske razvojne faze vzdolž dveh regionalnih alpskih struktur. V tektonski zgradbi ozemlja se pojavljata dve osnovni smeri tektonskih struktur, ki pa se v določeni meri tudi združita. Starejše geološke strukture potekajo približno v smeri od jugozahoda proti severovzhodu. Po Ljutomerskem prelomu bi lahko to smer imenovali ljutomerska smer, po Halozah pa haloška smer. V tej smeri poteka Haloška sinklinala, ki s svojim 
jedrom iz miocenskih kamnin sega na Plešivec. V isti smeri se vzporedno z njo kot nekakšna antiklinala pojavlja pas permskih kamnin, ki potekajo sklenjeno v smeri od Gabrnika čez Malotravniško dolino in Hrastovec, ter prek Frmile ter Tolstega vrha; manjši otok teh kamnin je še na območju Leneša, kjer je kraška jama Belojača. Drugo, mlajšo smer geoloških prelomov in struktur, potekajočih od severozahoda proti jugovzhodu, bi lahko poimenovali po Labotskem prelomu labotska smer in je začela nastajati nekje med zgornjim pliocenom ter kvartarjem. Ob tem desnozmičnem prelomu poteka zgornja dolina Dravinje. Ta prelom se vsaj deloma nadaljuje v Donački prelom, ki je ukrivljen v smer proti vzhodu. Medtem, ko območje Jadranske plošče zahodno od Labotskega preloma drsi proti severozahodu, pa je prav to drsenje na območju Haloz in Bočko-Maceljskega hribovja iz severa zavrto s pritiskom Pohorske grude, katere metamorfne kamnine se spuščajo pod obravnavano pokrajino prav ob Ljutomerskem prelomu (Fodor s sodelavci 2002). Posledica sta ukrivljanje in strižne napetosti, ki povzročajo nastanek prečnih prelomov (Žibret 2016). Še več prelomov različnih smeri je videti iz linearnih stikov med karbonatnimi in nekarbonatnimi kamninami na priloženih zemljevidih (slike 2-4).

Rečna mreža na Dravinjski strani hribovja se je razvila prečno na geološke strukture, vzdolžno prelomom pa sledi glavna odvodna dolina Dravinje. Medtem, ko Spodnja Frmilska dolina poteka prečno na haloško smer, pa dolina Bele (Poljčanski jarek) poteka prečno na labotsko smer. Potek obeh dolin kaže, da sta nastali in ohranili svoj prvotni potek še iz zelo nizkega reliefa, ki na površju še ni imel tako pestre kamninske zgradbe, kot jo lahko opazujemo danes. Vse to kaže na zelo hitro dvigovanje površja od zgornjega pliocena dalje (Bahar 2014). Tako Zgornja Frmilska dolina kot Malotravniška dolina (slika 6) potekata v majhnem tektonskem jarku med višje dvignjenimi apnenčastimi bloki, ki so ponekod še prekriti z nekarbonatnimi kamninami, kar je prikazano na geološkem prerezu prek Zgornje Frmilske doline (slika 7).

Na območju Frmilske doline opazujemo različno močno tektonsko preoblikovanost. Starejše kamnine permske in triasne starosti so bile večkrat tektonsko preoblikovane, zato dajejo videz "mozaika" iz večjih in manjših nepravilno oblikovanih grud. Sosednje grude so iz različnih kamnin, različnih starosti in nastalih v različnih okoljih. Iz njih zelo težko rekonstruiramo prvotno površje. Prav nasprotno pa so neogenske kamnine še vedno bolj ali manj povezane med seboj in so v nekakšnih gubah položene prek tektonsko veliko bolj preoblikovane podlage. Nekarbonatne kamnine prekrivajo na območju Frmilske doline omenjene grude starejših kamnin v obliki tanke krovnine. Tudi te so ob neotektonskih prelomih dvignjene ali spuščene ter premaknjene, vendar so ti premiki relativno majhni, zgolj nekaj deset metrski. Zato so te kamnine navidezno lepo upognjene po sedanjem površju in so bolj ali manj skladne s sedanjim reliefom. Na Dravinjski strani se dvigajo po pobočju skoraj do slemena, prek planot pa se spustijo v dno Zgornje Frmilske in Malotravniške doline, ter se prek razvodja na Sotelski strani slemena znova strmo spuščajo v dolino. Tega starejše tektonsko že močno preoblikovane kamnine ne izkazujejo. Prav takšna lega in manjša tektonska preoblikovanost nekarbonatnega pokrova kažeta, da te nekarbonatne kamnine niso permske starosti (Aničić in Juriša 1985a), temveč verjetno neogenske starosti. S temi se ponekod tudi površinsko stikajo.

\section{Popis vseh dolin}

Skupaj je bilo v porečju Frmilske doline preučenih 28 dolin (preglednici 1 in 2), še tri (preglednica 3) pa so bile preučene v sosednjih porečjih v neposredni bližini razvodnice. Od tega je 17 hidrološko aktivnih slepih dolin, 7 hidrološko neaktivnih slepih dolin ter še 7 fosilnih rečnih dolin, ki so na zemljevidih označene kot zakrasele doline (oznaka ZD).

Slike 2-4: Geološki prikaz Zgornje Frmilske in Malotravniške doline. $>$ str. 15-17 


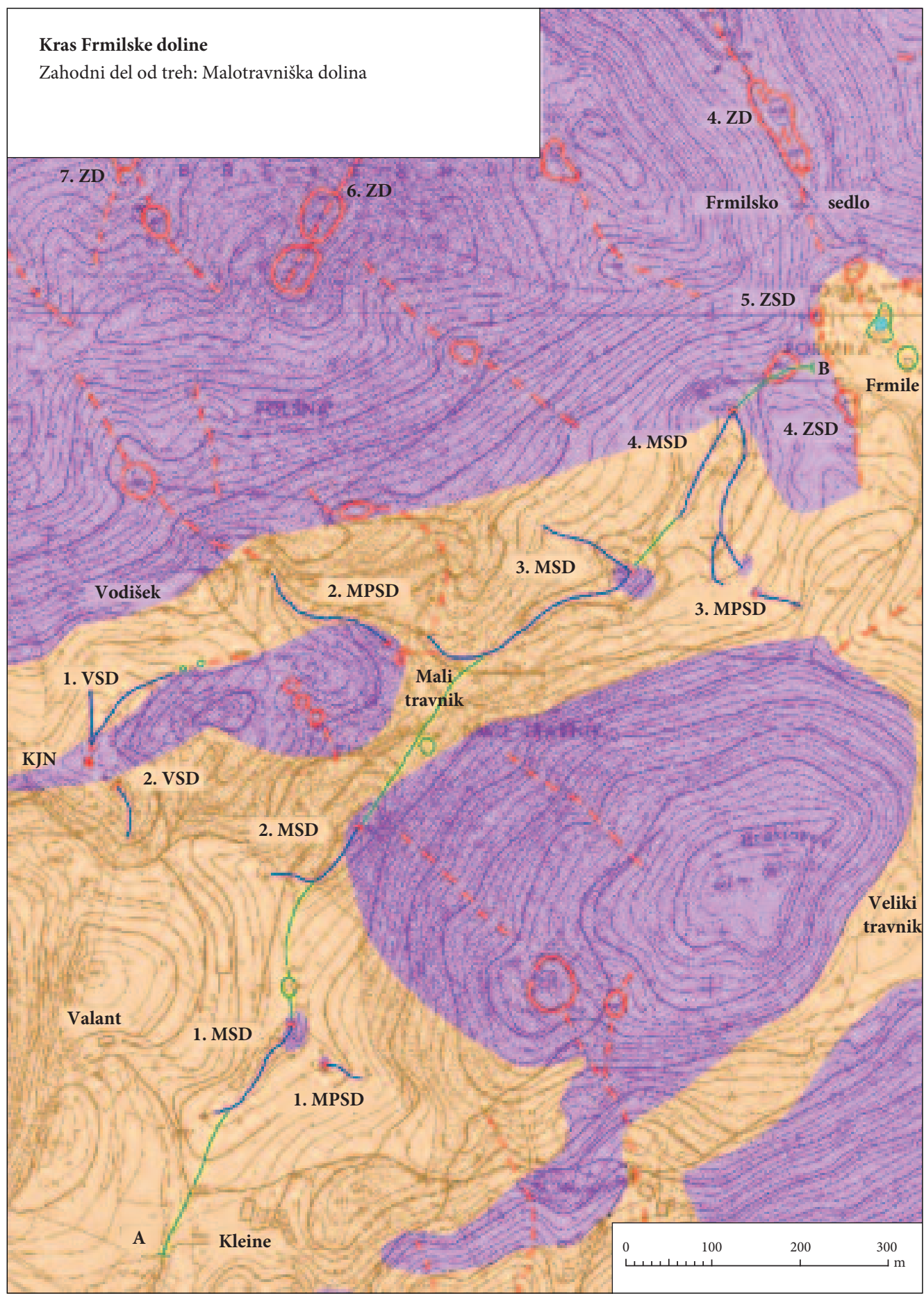




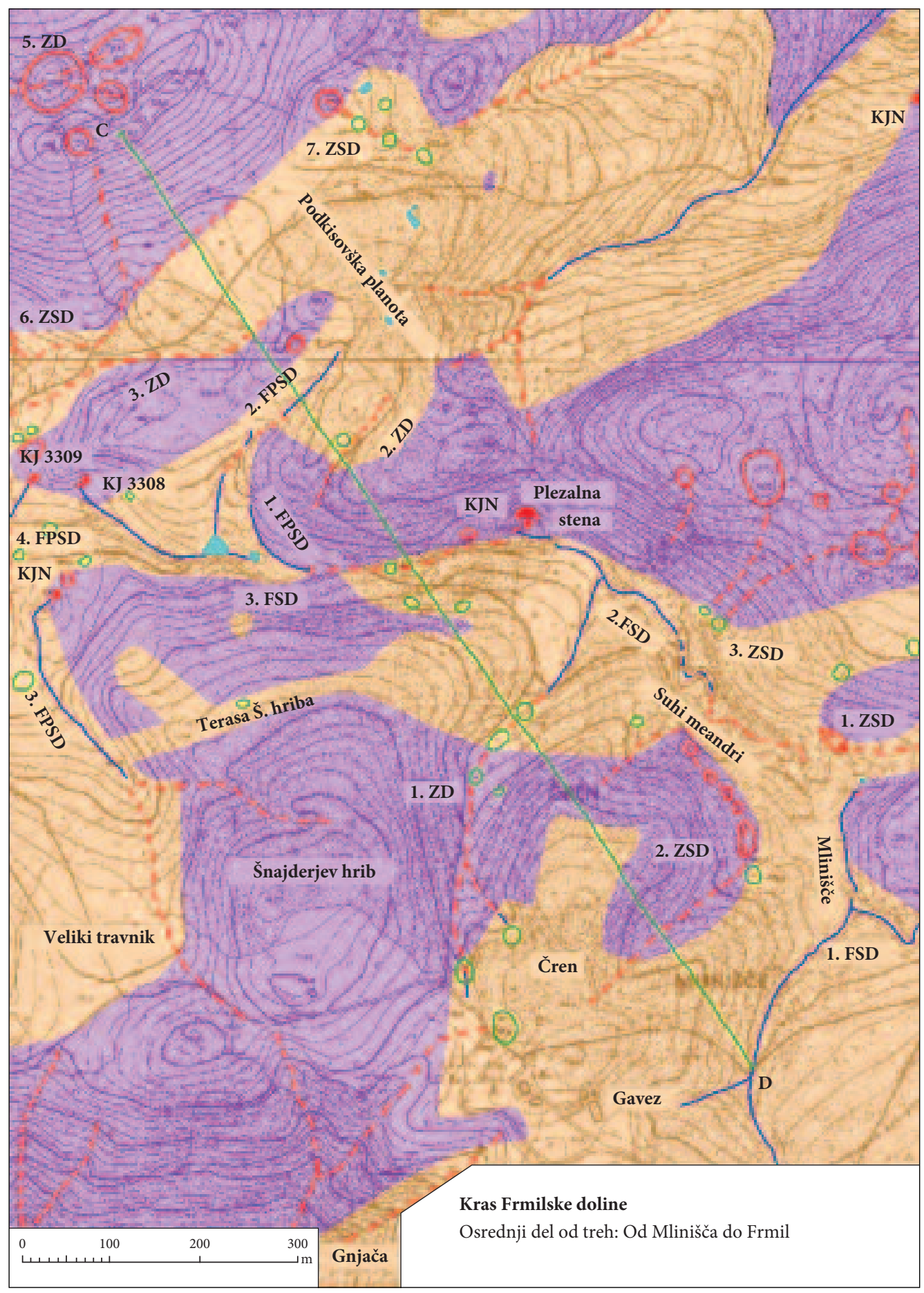




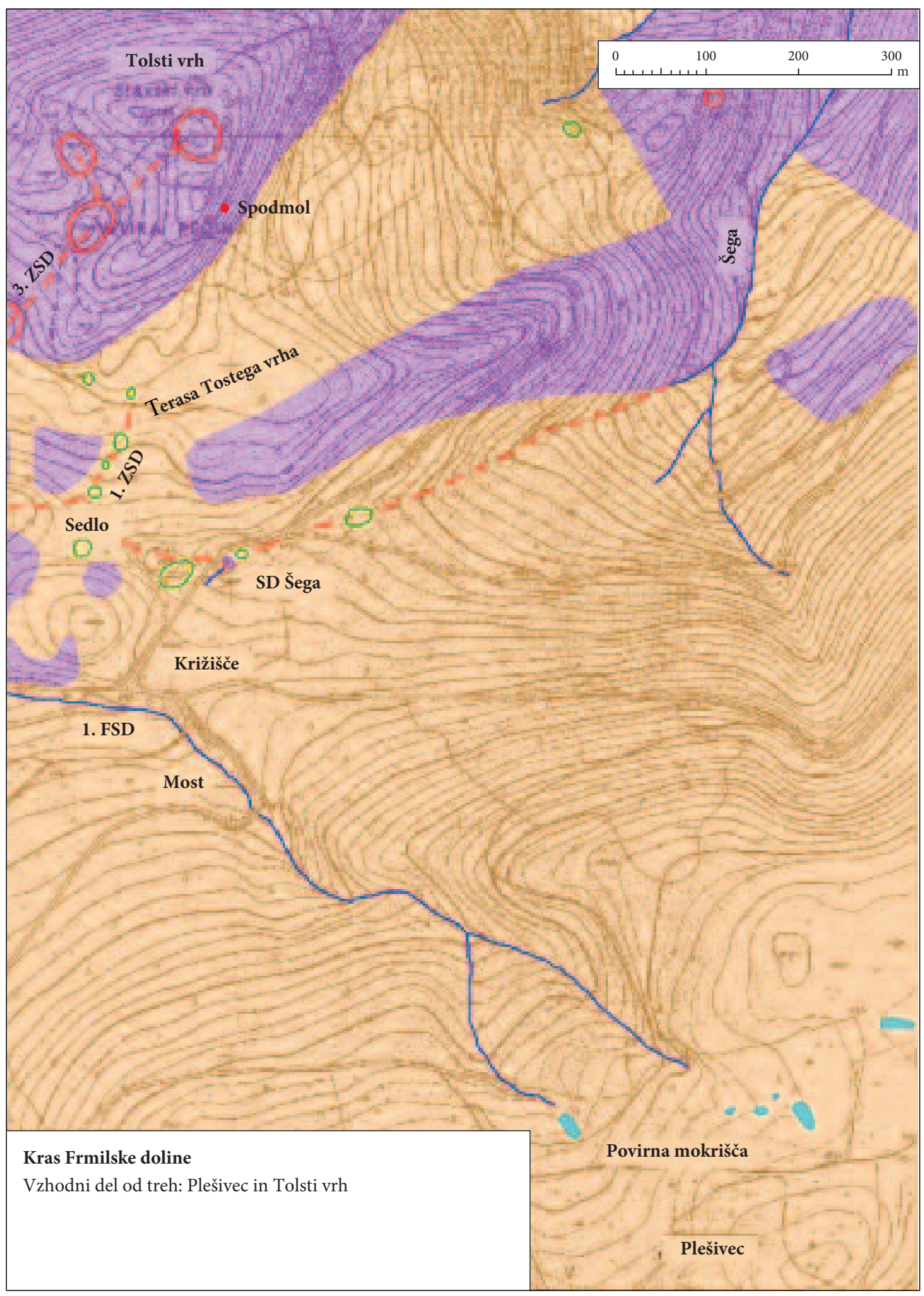




\section{Legenda zemljevidov in prerezov}

Merila zemljevidov in prerezov so povsod grafična, sever pa zgoraj.

Vir podlage zemljevidov: TTN-5, Listi: Rogatec 2, 3, 12 in 13. Geodetski zavod Slovenije 1991.

Avtor vsebine, zemljevidov in prerezov: Igor Bahar

Posamezni listi zemljevida so med seboj navpično zamaknjeni zaradi prilagajanja poteku doline (slika 1).

Globina karbonatnih kamnin pod nekarbonatnimi je zgolj domnevna.

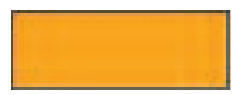

nekarbonatne kamnine: kremenov konglomerat, kremenov peščenjak, glinavec

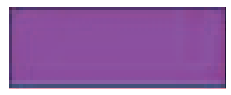

karbonatne kamnine: apnenec in dolomit

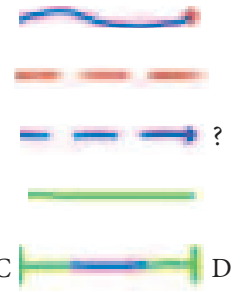

stalni ali občasni površinski vodni tok z aktivnim požiralnikom

potek zakrasele doline, zakrasele slepe doline, sufozijske doline

domnevna smer in globina podzemnega odtoka na prerezu Malotravniške doline

višina terase nad slepo dolino na vzdolžnem prerezu Malotravniške doline

potek prereza prek Malotravniške doline

in prereza prek Zgornje Frmilske doline

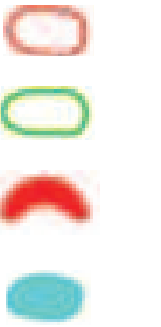

vrtača v karbonatnih kamninah

sufozijska vrtača v nekarbonatnih kamninah

plezalna stena - udorna stena, ki je nastala z udorom površja v kraško jamo

kal, presihajoča mlaka, povirno mokrišče

KJ 3308, KJN

kraška jama in spodmol: raziskana kraška jama s katastrsko številko, neraziskana in verjetna kraška jama z oznako KJN

3. FSD, 2. MSD oznaka glavne slepe doline: $\mathrm{F}=$ Frmilska, $\mathrm{M}=$ Malotravniška

2. MPSD oznaka pritočne slepe doline: $\mathrm{F}=$ Frmilska, $\mathrm{M}=$ Malotravniška

4. ZSD oznaka zakrasele slepe doline

3. ZD zakrasela dolina - oznaka za suho ali fosilno dolino

Slika 5: Legenda zemljevidov na slikah 2-4, geoloških prerezov na slikah 6-7 ter slike 8.

Slika 6: Geološki prerez prek Malotravniške doline. str. 19

Slika 7: Geološki prerez prek Zgornje Frmilske doline. str. 19 


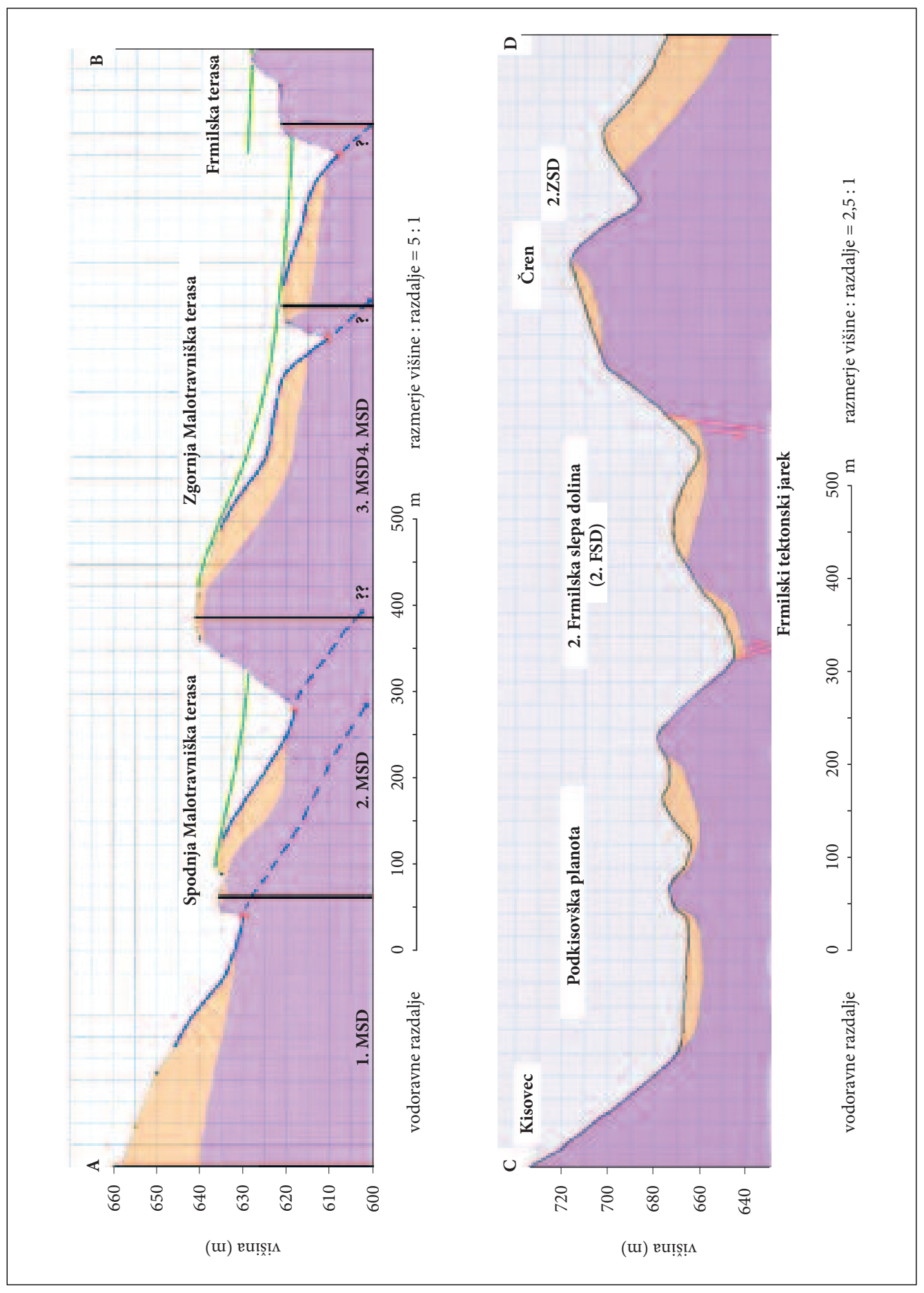


Preglednica 1: Enaindvajset dolin v Zgornji Frmilski dolini (slike 2-4).

Oznaka doline Lega in potek

1. FSD Prva Frmilska slepa dolina: od Plešivca do Mlinišča, kjer je bilo s sledenjem v požiralniku dokazana povezava s kraškimi izviri v Studenicah (Novak 1974) (sliki 3 in 4).

2. FSD Druga Frmilska slepa dolina: od Mlinišča do Plezalne stene s suhimi ali fosilnimi meandri in s še neraziskano kraško jamo, označeno na zemljevidu z oznako KJN (slika 3).

3. FSD Tretja Frmilska slepa dolina: od Plezalne stene do Frmil s požiralno kraško jamo pri partizanski bolnici (katastrska številka jame 3308) (slika 3).

1. FPSD Pritočna slepa dolina iz vzhodnega dela Podkisovške planote; nekdanji pritok 3. FSD (slika 3).

2. FPSD Pritočna slepa dolina na Podkisovški planoti, nekdanji pritok 3. FSD (slika 3).

3. FPSD Pritočna slepa dolina iz Velikega Travnika s še neraziskano kraško jamo (KNJ); nekdanji pritok 3. FSD (slika 3).

4. FPSD Pritočna slepa dolina, ki teče v požiralniško kraško jamo (katastrska številka jame 3309): verjetno nadaljevanje nekdanje 3. FPSD (slika 3).

1. ZSD Zakrasela pritočna slepa dolina iz Sedla pod Tolstim ali Stavskim vrhom; nekdanji pritok 2. FSD (sliki 3, 4).

2. ZSD Zakrasela pritočna slepa dolina na vzhodnem in severnem pobočju Črena; nekdanji pritok 2. FSD (slika 3).

3. ZSD Zakrasela pritočna slepa dolina iz Velike pečine pod Tolstim ali Stavskim vrhom; nekdanji pritok 2. FSD (sliki 3 in 4).

4. ZSD Zakrasela pritočna slepa dolina na južni strani Frmil (slika 2).

5. ZSD Zakrasela pritočna slepa dolina na zahodnem robu Frmil; verjetno nadaljevanje 4. ZSD (slika 2).

6. ZSD Zakrasela pritočna slepa dolina na severovzhodnem robu Frmil (sliki 2 in 3).

7. ZSD Zakrasela pritočna slepa dolina na vzhodni strani Kisovca; nekdanji pritočni del 5. ZD (slika 3).

1. ZD Zgoraj zakrasela pritočna dolina med Črenom in Šnajderjevim hribom; spodaj površinski pritok 2. FSD (slika 3).

2. ZD Zakrasela pritočna dolina zahodno od Plezalne stene; nekdanji pritok 3. FSD (slika 3).

3. ZD Zakrasela pritočna dolina iz Podkisovške planote na frmilske sufozijske vrtače (sliki 2 in 3).

4. ZD Zakrasela dolina prek Frmilskega sedla $\mathrm{z}$ nadaljevanjem v dolino Toplega potoka vse do kraških izvirov v Studenicah (slika 2).

5. ZD Zakrasela pritočna dolina iz Kisovca v dolino Toplega potoka (sliki 2 in 3).

6. ZD Zakrasela dolina iz Drevesnice v dolino Toplega potoka (slika 2).

7. ZD Dve zakraseli dolini na zahodu Drevesnice, ki se nižje na severnem pobočju združita v skupno zakraselo dolino z nadaljevanjem v dolino Toplega potoka (slika 2). 
Preglednica 2: Sedem dolin v Malotravniški dolini (sliki 2 in 6).

Oznaka doline Lega in potek

1. MSD Prva Malotravniška slepa dolina pod domačijama Kleine in Valant (sliki 2 in 6).

2. MSD Druga Malotravniška slepa dolina jugozahodno od Malega travnika (sliki 2 in 6).

3. MSD Tretja Malotravniška slepa dolina severovzhodno od Malega travnika (sliki 2 in 6).

4. MSD Četrta Malotravniška slepa dolina jugovzhodno od Frmil (sliki 2 in 6).

1. MPSD Prva Malotravniška pritočna sufozijska slepa dolina, nekdanji pritok 1. MSD (slika 2).

2. MPSD Druga Malotravniška pritočna slepa dolina, jugovzhodno od domačije Vodišek, nekdanji pritok 3. MSD. Zgornji del doline je že popolnoma zakrasel (slika 2).

3. MPSD Tretja Malotravniška pritočna sufozijska slepa dolina, nekdanji pritok 4. MSD (slika 2).

Preglednica 3: Tri doline v sosednjih porečjih (sliki 2 in 4).

Oznaka doline Lega in potek

SD Šega Slepa dolina v povirju potoka Šega severno od Križišča (slika 4).

1. VSD Slepa dolina južno od domačije Vodišek na severni strani grebena karbonatnih kamnin in z neraziskano kraško jamo (KJN) (slika 2).

2. VSD Slepa dolina južno od domačije Vodišek na južni strani grebena (slika 2).

\section{Potek zakrasevanja Frmilske doline}

V Frmilska dolini so ohranjene reliefne oblike rečnega in kraškega reliefa. Ob njih so ohranjene še prehodne reliefne oblike, ki so nastale s preobrazbo rečnega v kraški relief. Te tri glavne stopnje preobrazbe reliefa so shematično prikazane na sliki 8 . Dolina je imela v preteklosti v celoti rečni relief. Zakrasevanje je potekalo v šestih razvojnih stopnjah. Pogoj za takšen razvoj je relativno tanka vodoravna plast nekarbonatnih kamnin (kremenovih konglomeratov, kremenovih peščenjakov in glinavcev), ki ležijo na podlagi iz karbonatnih kamnin (apnencev in dolomitov).

1. razvojna stopnja: Površinsko porečje na nekarbonatnih kamninah, obdano z griči iz karbonatnih kamnin

Celotna Frmilska dolina je nastala na površju iz nekarbonatnih kamnin, na katerem je bil razvit rečni relief. Potoka Zgornje Frmilske doline in Malotravniške doline sta se zlivala na Frmilah, od koder je voda površinsko odtekala po dolini Toplega potoka vse do Dravinje. Zaradi erozije nekarbonatnih kamnin, so iz površja najprej pogledali najvišji deli iz karbonatnih kamnin. Ti griči ki danes obdajajo dolino so Hrastovec, Šnajderjev hrib, Tolsti vrh, Kisovec in Drevesnica (slika 1). Na njihovem površju najdemo fosilne doline, ki so danes povsem zakrasele. Te doline so označene z oznakami 3. ZSD, 5. $\mathrm{ZD}, 6 . \mathrm{ZD}$ in 7. ZD (slike 2-4). $\mathrm{V}$ teh primerih so se doline preoblikovale iz rečnega v kraški relief. 
2. razvojna stopnja: Nastanek sufozijskih kraških oblik, obviselih dolin ter teras in ravnikov na nekarbonatnih kamninah

Plast nekarbonatnih kamnin se je zaradi erozije in denudacije tako stanjšala, da je površinska voda začela pronicati skozi njo v spodaj ležeče karbonatne kamnine, kjer ustvarja podzemne kraške oblike. Pronicanje vode skozi nekarbonatne kamnine je povzročilo tudi nastanek vrtač, majhnih dolin brez površinskih vodnih tokov in požiralnike v nekarbonatnih kamninah. Primere sufozije pa najdemo v dolinah z oznako 1. MPSD in 2. FPSD (sliki 2 in 3). Takšno površje lahko imenujemo tudi prikriti kras (Gams 2003) ali angleško subjacent karst (Goudie 2004, 755).

Zaradi pronicanja vode v podzemlje se je znatno zmanjšal površinski vodni odtok in s tem njegova erozijska moč. Zaradi tega erozijsko poglabljanje doline ni več moglo slediti tektonskemu dvigovanju površja in sta Zgornja Frmilska in Malotravniška dolina postali obviseli dolini, več kot $300 \mathrm{~m}$ nad kraškimi izviri pri Studenicah oziroma okoli $350 \mathrm{~m}$ visoko nad dolino Dravinje.

V Zgornji Frmilski in v Malotravniški dolini so ohranjene rečne terase v višini nekdanjega dna obvisele doline. Njim podobne uravnave v nekarbonatnih kamninah najdemo tudi na Podkisovški planoti, na terasi Tolstega vrha, na Velikem Travniku in na Črenu (slike 2-4).

\section{3. razvojna stopnja: Nastajanje prvih zaporednih slepih dolin}

Zaradi neravne, tektonsko preoblikovane podlage iz karbonatnih kamnin, je ta ponekod pogledala na površje tudi v samem dnu doline. Na takšnih mestih so površinski potoki preusmerili svoj odtok skozi požiralnike $\mathrm{v}$ kraško podzemlje. Vsak greben karbonatnih kamnin v dolinskem dnu je povzročil nastajanje nove zaporedne slepe doline, na primer 1. MSD in 3. MSD (sliki 2 in 6). Zaradi vzdolžnega prereza potoka se je to najprej zgodilo $\mathrm{v}$ spodnjem toku, potem pa se je z zadenjsko erozijo prestavljalo

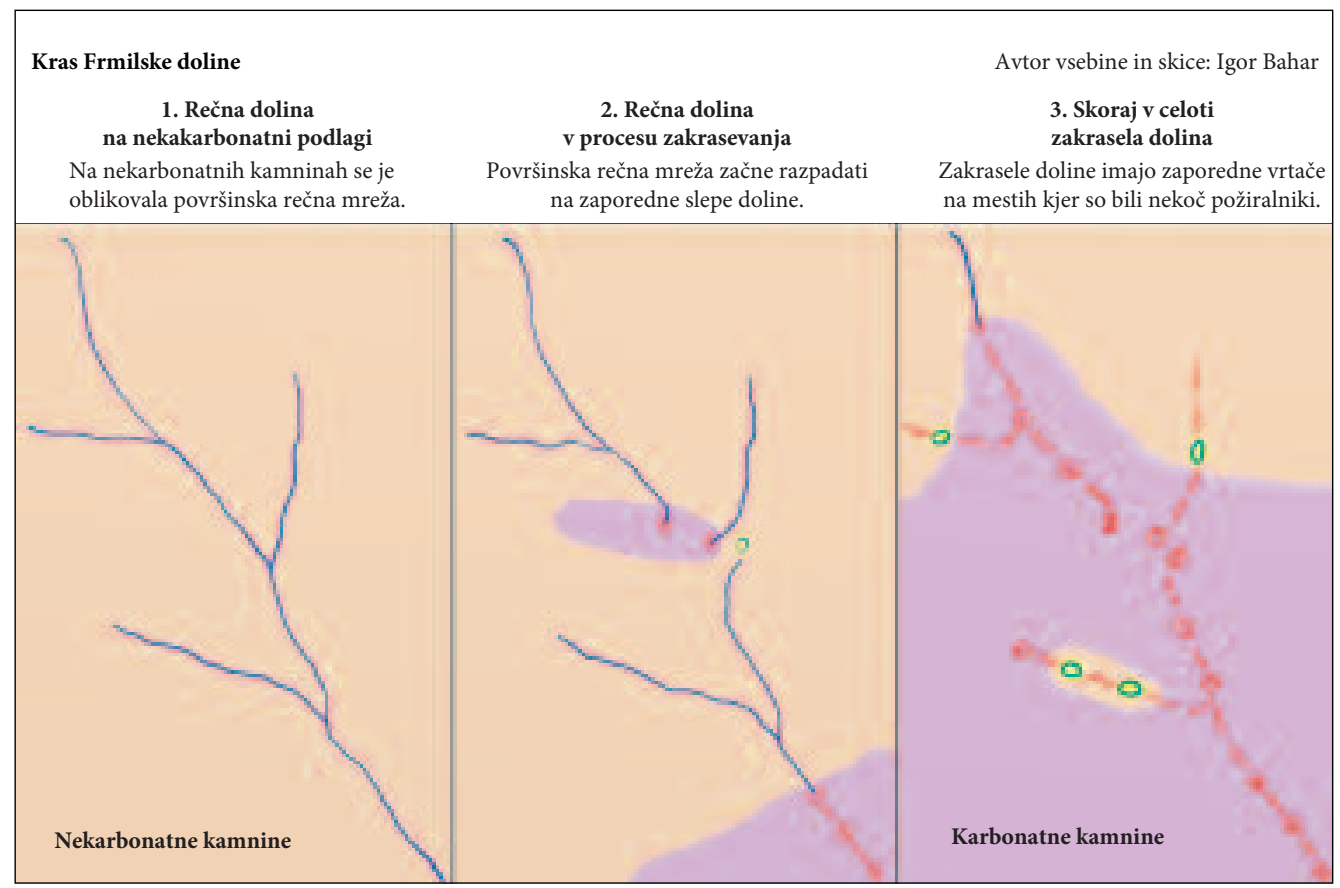

Slika 8: Shematičen prikaz razvoja reliefa v Frmilski dolini. 
po toku navzgor. Najstarejša slepa dolina je potemtakem nastala na spodnjem delu prvotne doline, po toku navzgor pa so nastajale vse mlajše doline. Najmlajše slepe doline so tiste, kjer voda še danes priteka na kras. Najbolj nazorno se to vidi v Zgornji Frmilski dolini, kjer ima 1. FSD še povsem rečni relief, 2. FSD ima večinoma zakraselo suho dolino s suhimi ali fosilnimi meandri, 3. FSD pa takšnih meandrov nima več in so prvotno dolino "posvojili« nekdanji pritoki (sliki 3 in 4). Suhi ali fosilni meandri so dokaz, da se je prehod iz rečnega $v$ kraški relief zgodil nedolgo nazaj, verjetno v srednjem holocenu. Prav tako imamo dokaze za opisan razvoj tudi v terasah na Frmilah in v Malotravniški dolini. Najvišja terasa je Frmilsko sedlo, okoli 15 m nižja pa je Frmilska terasa pod njim. Od nje je nekoliko nižja Zgornja Malotravniška terasa nad 3. in 4. MSD, še nižja pa je Spodnja Malotravniška terasa nad 1. in 2. MSD (sliki 2 in 6).

\section{4. razvojna stopnja: Razpad prvotne slepe doline na več manjših slepih dolin ter nastanek umikalnih stadijev $v$ razvoju slepih dolin}

Procesa erozije in korozije nista enakomerna na celotnem površju. Na stiku različnih kamnin se učinkovitost obeh procesov močno poveča. To se vidi v intenzivnem poglabljanju slepih dolin prav pred požiralniki, na primer pri 3. FSD, 3. MSD in 4. MSD (sliki 2 in 3), kjer so vodotoki poglobili svoje struge $\mathrm{v}$ terase obviselih dolin in $\mathrm{v}$ matično podlago, ki je večinoma glinavec. Ob tem je proces erozije nekarbonatnih kamnin na površju v ravnovesju s procesom spiranja sedimentov skozi kraške votline v podzemlju (s prepustnostjo zakraselega podzemlja), saj bi se sicer podzemne votline zapolnile s sedimenti in bi voda začela zastajati na površju, kar pa se ne dogaja.

Z erozijo nekarbonatnih kamnin $\mathrm{v}$ dnu slepih dolin, površinska voda postopno razgalja čedalje več karbonatnih izdankov, pri čemer slepe doline razpadajo na več manjših slepih dolin, na primer med 1. MSD in 2. MSD (sliki 2 in 6), kar je vzrok za večje število zaporednih slepih dolin.

Ponekod so se $\mathrm{z}$ zadenjsko erozijo $\mathrm{v}$ dnu slepih dolin $\mathrm{v}$ nekarbonatnih kamninah požiralniki prestavili nekaj metrov proti toku, kjer je voda našla nov požiralnik, na primer na koncu 1. FSD na Mlinišču (slika 3). Posledica tega so hidrološko neaktivni deli slepih dolin, ki z ohranjenimi vrtačami kažejo na postopno umikanje požiralnikov proti toku. To bi lahko imenovali umikalni stadiji v razvoju slepe doline, na primer pri 2. ZSD (slika 3).

\section{5. razvojna stopnja: Presihanje ostankov glavnega vodotoka in posvojitev glavne doline po nekdanjih pritokih}

Ko glavni vodotok v dolinskem dnu v celoti presahne, obstoječo dolino »posvojijo« njegovi nekdanji pritoki, ki sedaj delujejo kot samostojne hidrološko aktivne slepe doline, na primer pri 2. FPSD in 4. FPSD (slika 3). Ti nekdanji pritoki se iz spodnjih delov pobočij, ki so še vedno prekrita z nekarbonatnimi kamninami, površinsko zlivajo v dno doline. Pri tem se končni del vodotoka pogosto obrne $\mathrm{v}$ smeri proti prvotnemu dolinskemu toku, na primer pri 1. FPSD in deloma pri 3. FPSD ter 2. MPSD (sliki 2 in 3). Ta oblika je nastala prav zaradi umikalnih stadijev v razvoju slepih dolin in zaradi kraške pretočitve v podzemni odtok zgornje slepe doline.

\section{6. razvojna stopnja: Nastanek povsem kraškega površja}

Razvojne stopnje od 3 do 5 so prehodne stopnje med rečnim in kraškim reliefom, s popolno odstranitvijo nekarbonatnih kamnin pa se je oblikovalo povsem kraško površje. Nekdanje rečne doline so se spremenile v zakrasele fosilne doline in hidrološko neaktivne slepe doline. Kjer so bili nekoč požiralniki v slepih dolinah, so sedaj ohranjene le zaporedne vrtače, na primer v 2. ZSD in v 4. ZD (sliki 2 in 3).

Površje se zaradi delovanja različnih geomorfnih procesov še naprej spreminja, zato so oblike nekdanje rečne mreže na površju vse bolj zabrisane. Obstoj in lego nekdanjega površinskega rečnega omrežja 
na nekarbonatni podlagi nam dokazujejo kremenovi prodniki v jamskih rovih, kot na primer v Osovniški jami na Pijovcih pri Mestinju (Bahar 2001).

\section{Sklep}

V Frmilski dolini so ohranjene reliefna oblike rečnega in kraškega reliefa. Ob njih so ohranjene še prehodne reliefna oblike, ki so nastale s postopno preobrazbo rečnega v kraški relief. Te nam omogočajo razumeti preoblikovanje površja iz rečnega v kraški relief.

Zaradi erozije nekarbonatnih kamnin, ki pokrivajo karbonatne, slednje zaradi erozije krovnine postopno prihajajo na površje, dokler povsem ne prevladajo. Takšen prehod se je zgodil tudi drugod po Sloveniji, kjer so bile nekarbonatne kamnine s prvotnim rečnim reliefom odstranjene (Pleničar, Ogorelec in Novak 2009). Sledi takšne preobrazbe še vedno lahko opazimo v današnjem kraškem reliefu.

V raziskavi je bilo s podrobnim kartiranjem karbonatnih in nekarbonatnih kamnin v merilu 1:5000 ugotovljeno, da v Frmilski dolini nimamo zgolj posamičnih kraških pojavov, temveč da je celotna dolina enovit kraški pojav, ki nam omogoča spoznavanje procesa zgodnjega zakrasevanja. Dolina je v tem smislu edinstven primer v Sloveniji (Zemljepisni ... 2017).

Ostajajo pa številna odprta vprašanja, na primer starost ter sklenjenost permskih in oligocensko miocenskih nekarbonatnih kamnin, vpliv neotektonskega dviganja na preoblikovanje površja, starost suhih ali zakraselih meandrov ter teras in ravnikov, hitrost zakrasevanja $\mathrm{z}$ nekarbonatnimi kamninami pokritega krasa ter soodvisno nastajanje kraških in novih rečnih oblik na nekarbonatnem površju ali globina pretakanja kraške vode pod nekarbonatnim površjem.

Zahvala: Prof. dr. Juriju Kunaverju se zahvaljujem za skrben pregled prvega besedila članka, popravke, nasvete in spodbude. Za mnoge koristne napotke se zahvaljujem tudi dr. Mitji Prelovšku z Inštituta za raziskovanje krasa ZRC SAZU. Članom Geomorfološkega društva Slovenije in še posebej predsednici društva dr. Mateji Ferk se zahvaljujem za skupni ogled opisanega terena na društveni ekskurziji. Za pregled in popravke angleškega besedila se zahvaljujem gospe Veri Lamut.

\section{Viri in literatura}

Aničić, B., Juriša, M. 1985a: Osnovna geološka karta SFRJ 1:100.000, list Rogatec. Zvezni geološki zavod. Beograd.

Aničić, B., Juriša, M. 1985b: Osnovna geološka karta SFRJ 1:100.000, tolmač lista Rogatec. Zvezni geološki zavod. Beograd.

Bahar, I. 2001: Odkrili smo novo kraško jamo. Rogaške novice, 30. 3. 2001.

Bahar, I. 2014: Oblikovanje rečnega reliefa v Sotelsko-Savinjski pokrajini: geološke osnove reliefa. Geografija v šoli 23, 2-3.

Brancelj (brez imena) 1984: Požiralnik pri partizanski bolnici, Dopolnilni jamarski zapisnik za kraško jamo št. 3308, 13.7. 1984. Kataster jam Jamarske zveze Slovenije. Ljubljana.

Fodor, L., Jelen, B., Marton, E., Rifelj, H., Kraljić, M., Kevrić, R., Matron, P., Koroknai, B., Baldi-Beke, M. 2002: Miocene to Quaternary deformation, stratigraphy and paleogeography in Northeastern Slovenia and Southwestern Hungary. Geologija 45-1. DOI: https://doi.org/10.5474/geologija.2002.009 Gams, I. 2003: Kras v Sloveniji v prostoru in času. Ljubljana.

Gospodarič, R. 1982: O kraških pojavih Boča. Zbornik Občine Slovenska Bistrica 1. Slovenska Bistrica. Goudie, A. (ur.) 2004: Encyclopedia of Geomorphology. New York.

Medmerežje 1: http://www.geopedia.si/ (12.4.2017). 
Novak, D. 1969a: Požiralnik pri partizanski bolnici, Jamarski zapisnik za kraško jamo št. 3308. Kataster jam Jamarske zveze Slovenije. Ljubljana.

Novak, D. 1969b: Požiralnik pri Formili, Jamarski zapisnik za kraško jamo št. 3309. Kataster jam Jamarske zveze Slovenije. Ljubljana.

Novak, D. 1974: Osameli kras v podravskem delu SR Slovenije. Acta carsologica 6.

Novak, D. 1982: Nekaj opazovanj izvira Studeniškega potoka pod Bočem. Zbornik Občine Slovenska Bistrica 1. Slovenska Bistrica.

Občina Rogaška Slatina: karta občine 1 :25.000. Rogaška Slatina, 1995.

Pažon, M. 2016: Bočka uganka. Zbirka ljudskih pripovedi iz naših krajev. OŠ Rogaška Slatina.

Pleničar, M., Ogorelec, B., Novak, M. (ur.) 2009: Geologija Slovenije. Ljubljana.

Rogaška Slatina z Bočem in Donačko goro: planinska karta 1:25.000. Ljubljana, 1989.

Temeljni topografski načrt Republike Slovenije 1:5.000, listi: Rogatec 2, 3, 12, 13. Ljubljana, 1991.

Trček, B., Leis, A. 2017: Pregled izotopskih raziskav podzemne vode v razpoklinskem vodonosnem sistemu na območju Rogaške Slatine. Geologija 60-1. DOI: https://doi.org/10.5474/geologija.2017.004

Trobič (brez imena) 1984: Požiralnik pri Formili, Dopolnilni jamarski zapisnik za kraško jamo št. 3309, 13. 7. 1984. Kataster jam Jamarske zveze Slovenije. Ljubljana.

Zemljepisni krožek II. osnovne šole Rogaška Slatina. Kraške jame Boča in Formilske doline. Raziskovalna naloga. Rogaška Slatina, 2013

Zemljepisni krožek II. osnovne šole Rogaška Slatina. Polgoli kras Malotravniške doline v Krajinskem parku Boč-Donačka gora. Raziskovalna naloga. Rogaška Slatina, 2016

Zemljepisni krožek II. osnovne šole Rogaška Slatina. Polgoli kras Frmilske doline v Krajinskem parku Boč-Donačka gora. Poučni film. Rogaška Slatina, 2017. Medmrežje: https://www.youtube.com/user/ javornik1000/ (12.5.2017).

Žibret, L. 2016: Prispevek k boljšemu razumevanju strukturnih značilnosti in tektonskih faz območja Boča v coni Periadriatskega preloma. Geologija 59-2. DOI: https://doi.org/10.5474/geologija.2016.015

\section{Summary: Karst of Frmile Valley in the Landscape Park Boč-Donačka Gora}

(translated by the author)

In the Frmile valley there are preserved geomorphological features of fluvial and karst relief, but also many transitional features from fluvial to karst landscape. This allows us to understand the transformation from a fluvial to a karstic landscape (figure 8). Such transformation took place also elsewhere, where the underlying Mesozoic and older carbonate rocks were first exposed through the overlying largely non-carbonate Tertiary rocks and eventually completely prevailed on the surface. The traces of this transformation can still be seen in today's karst relief.

In this study, a detailed mapping of carbonate and non-carbonate rocks at a scale of 1:5,000 was performed. It was found that not only individual karstic features exist in the valley, but that the whole valley is uniform karst phenomenon, which allows us to learn about the early karstic process. In this sense, the whole valley is landmark of national importance.

The karstic process took place in six evolution phases. Such evolution is the result of a relatively thin horizontal layer of non-carbonate rocks (quartz conglomerates, quartz sandstones and claystones) overlying thick carbonate rocks (limestones and dolomites).

$1^{\text {st }}$ evolution phase: Surface water drainage on non-carbonate rocks, surrounded by low hills of carbonate rocks:

The whole Frmile Valley drainage basin was initially located on a surface of non-carbonate rocks. The streams of Zgornja Frmilska dolina (Uper Frmila Valley) and Malotravniška dolina (Malotravniška 
Valley) confluence on Frmila, from where a single stream flowed through Topli potok Valley to the Dravinja Valley. Due to the erosion of the non-carbonate rocks, parts of underlying carbonate rocks become uncovered. These low hills of carbonate rocks surrounding the valley are Hrastovec, Šnajderjev hrib, Tolsti vrh, Kisovec and Drevesnica (figure 1). On their surface one can still see the fossil remains of the original river networks marked as 3. ZSD, 5. ZD, 6. ZD and 7. ZD (figures 2-4). In these cases, the valleys were immediately transformed from fluvial to karst relief.

$2^{\text {nd }}$ evolution phase: Formation of suffosion karst features, hanging valleys and surface water terraces and plateaus on non-carbonate rocks:

Due to erosion, the layer of non-carbonate rocks became so thin, that surface water began to seep through it into the underlying carbonate rocks and, by corrosion, created underground karst phenomena. The seepage of water through non-carbonate rocks also formed dolines, tiny valleys without the surface water flow and ponors due to the process of suffosion. Such examples can be found in the valleys marked 1. MPSD and 2. FPSD (figures 2-3). Such surface is called subjacent karst (Goudie 2004, 755).

Due to seepage of water into the underground, the surface water runoff was significantly decreased and so was its erosive power. Therefore, the erosion deepening the valley could no longer keep pace with the tectonic lifting of the surface, which made the Uper Frmila Valley and Malotravniška Valley hanging valleys, about $350 \mathrm{~m}$ high above the Dravinja Valley.

In both valleys, river terraces at the bottom of the former hanging valleys have been preserved. Similar plateaus can be found on the Podkisovška plateau, terrace of Tolsti vrh, on Veliki Travnik and on Čren (figures 2-4).

\section{$3^{\text {rd }}$ evolution phase: Formation of first successive blind valleys:}

Due to the uneven tectonically transformed carbonate rocks, they eventually became uncovered at the very bottom of the valley. In such places surface water flow was diverted through ponors to the karst underground. Each exposure of carbonate rocks in the valley bottom indicated the formation of a new successive blind valley, such as 1. MSD and 3. MSD (figures 2 and 6). Due to the longitudinal profile of the stream, this first happened in the lower part of the valley and then moved upstream by head ward erosion. Thus, the oldest blind valley is at the lowest part of the original stream and the youngest is upstream. The youngest blind valleys are the ones where water is only now flowing into the karst. In the Upper Frmila Valley, 1. FSD (First Frmila successive Blind Valley) has almost entirely fluvial relief. 2. FSD (the second) has mostly karstic landscape with dry or fossil meanders. The 3. FSD is even more karsticly transformed and without meanders (figures 3-4). Dry or fossil meanders are the proof, that transition from fluvial to karstic landscape happened recently, probably sometime in the middle of Holocene. Similar proofs can be seen in Malotravniška Valley. The highest terrace is in Frmilsko sedlo (Frmile Pass), about $15 \mathrm{~m}$ lover is Frmile terrace, and even lover is Zgornja Malotravniška terasa (Upper Malotravniška terrace) above 3. and 4. MSD. Even lover is Spodnja Malotravniška terasa (Lover Malotravniška terrace) above 1. and 2. MSD (figures 2 and 6).

$4^{\text {th }}$ evolution phase: Disintegration of the former blind valley into several smaller blind valleys and into the withdrawing stages in the evolution of blind valleys:

The processes of erosion and corrosion are not uniform all over the surface. It is at the contact of different kinds of rocks that the intensity of both processes increases. This can be seen in the intense deepening of blind valleys right in front of the ponors, for example in 3. FSD, 3. MSD and 4. MSD (figures 2-3). These streams deepened their channels below the terraces of hanging valleys and into the bedrock mostly of claystone. In this process, the surface erosion of the non-carbonate rocks was in the equilibrium with the washing away of sediments through underground karst cavities (with permeability of karst underground). Otherwise, the underground cavities would become filled with sediments and the water would stagnate on the surface, but this doesn't happen. 
With the erosion of the non-carbonate rocks at the bottom of blind valleys, surface stream uncovered new carbonate rocks. This has led to a disintegration of the original blind valley into two separate blind valleys, for example between 1. MSD and 2. MSD (figures 2 and 6). That is why there are so many blind valleys in Frmile drainage basin.

In some places, the ponor of certain stream moved by head ward erosion few meters upstream, where water found a new ponor, for example at the end of the 1. FSD on Mlinišče (figure 3). The result of this process are relict parts of blind valleys, where preserved dolines show the gradual withdrawal of the ponors head ward of the initial water flow. This could be called the withdrawing stages in the evolution of blind valleys, such as in 2 . ZSD (figure 3 ).

$5^{\text {th }}$ evolution phase: The drying up of the remains of the main stream and the adoption of the main valley by its former tributaries:

When the main stream in the valley bottom completely disappears in the karst underground, the existing valley is adopted by its former tributaries, which are now independent hydrologically active blind valleys, as in 2. FPSD and 4. FPSD (figure 3). They flow from the lower parts of the slopes that are still covered with non-carbonate bedrock. In such a situation, the final part of the stream often turns against the direction of the initial valley flow, such as in 1. FPSD and partly in 3. FPSD and 2. MPSD (figures 2-3). This form developed due to the withdrawing stages in the evolution of blind valleys and because they decant to the underground drainage of the upper blind valley.

\section{$6^{\text {th }}$ evolution phase: The formation of entirely karst surface:}

The evolution phases from 3rd to 5th are transitional phases between fluvial and karst landscape. With the complete removal of non-carbonate rocks, the valley changes to a completely karst surface. Former stream valleys changes into dry or fossil karst valleys and hydrologically inactive blind valleys. In the places of the former ponors of blind valleys, there are series of successive dolines, as in the 2 . ZSD and 4. ZD (figures 2-3).

Surface is further transformed by different geomorphic processes. Features of former surface streams are more and more blurred. The existence and location of former surface streams network on non-carbonate bedrock are evidenced by quartz pebbles discovered in cave passages, for example in the cave Osovniška jama at Pijovci near Mestinje (Bahar 2001). 